\title{
Related factors of periodontal health among Chinese middle school students, findings from a national cross-sectional survey
}

Jingyu Zhan ${ }^{1+}$, Yu Zhang ${ }^{1 \dagger}$, Xing Wang ${ }^{2}$, Baojun Tai ${ }^{3}$, Deyu Hu ${ }^{4}$, Huancai Lin ${ }^{5}$, Bo Wang ${ }^{2}$, Yan $\mathrm{Si}^{6}$, Chunxiao Wang ${ }^{7}$, Shuguo Zheng ${ }^{6}$, Xuenan Liu', Wensheng Rong ${ }^{6}$, Weijian Wang ${ }^{6}$, Xiping Feng ${ }^{1 *}$ and Xi Chen ${ }^{{ }^{*}}$

\begin{abstract}
Background: To investigate the related risk factors of periodontal health status among Chinese middle school students.

Methods: This study is a part of the Fourth National Oral Health Epidemiological Survey, which is by far the largest oral epidemiological survey in China, including all provinces, municipalities and autonomous regions in mainland China. A multi-stage stratified sampling method was used to select middle school students aged 12-15 from the sampled middle school for investigation. The survey consisted of two parts: oral examination and questionnaire survey. The oral examination included gingival bleeding and calculus. The questionnaire included sociodemographic information, oral health knowledge, attitudes and behaviors. Logistic regression and generalized linear mixed model were used to investigate the risk factors of gingival bleeding and calculus.

Results: A total of 118,514 middle-school students has been examined. Less gingival bleeding $(\mathrm{OR}=0.746, \mathrm{Cl} 0.718-$ $0.774)$ and calculus ( $\mathrm{OR}=0.550, \mathrm{Cl} 0.529-0.527)$ were found in 12-year-old group compared to 15-year-old group. The periodontal health status of males was worse than that of females (gingival bleeding $\mathrm{OR}=1.102, \mathrm{Cl} 1.074-1.132$, calculus $O R=1.258, \mathrm{Cl} 1.223-1.295$ ). Besides age and gender, region, living place, ethnic groups, family structure, parent's education level, oral health knowledge and behavior were also related to gingival bleeding and calculus.

Conclusions: Gingival bleeding and calculus occurred most of 12-15 years old adolescents in China. Several related factors, such as gender, age, ethnicity, father's education level, oral health knowledge and behavior, were found in multi-factorial models. The impact of province should arouse people's attention.
\end{abstract}

Keywords: Gingival bleeding, Calculus, Adolescent, Generalized linear mixed model

*Correspondence: fxiping1808@qq.com; 371921358@qq.com †Jingyu Zhan and Yu Zhang contributed equallyto this study and share first authorship

1 Shanghai Key Laboratory of Stomatology and Shanghai Research Institute of Stomatology, Department of Preventive Dentistry, Shanghai Ninth People's Hospital, College of Stomatology, National Clinical Research Center for Oral Diseases, Shanghai Jiao Tong University School of Medicine, 639 Zhizaoju Road, Shanghai, People's Republic of China Full list of author information is available at the end of the article

\section{Background}

Severe periodontitis, affecting approximately more than one-tenth of whole population in the world, is one of the most common oral diseases [1]. It is regarded as a public health problem due to the high prevalence, impairing the quality of life and causing disability [2,3]. Periodontitis represents a range of clinical manifestations from mild subclinical inflammation to advanced destructive forms, leading to tooth loss [4]. Diagnosis is based mainly on clinical assessment of surrogate markers such as probing

(c) The Author(s) 2021. Open Access This article is licensed under a Creative Commons Attribution 4.0 International License, which permits use, sharing, adaptation, distribution and reproduction in any medium or format, as long as you give appropriate credit to the original author(s) and the source, provide a link to the Creative Commons licence, and indicate if changes were made. The images or other third party material in this article are included in the article's Creative Commons licence, unless indicated otherwise in a credit line to the material. If material is not included in the article's Creative Commons licence and your intended use is not permitted by statutory regulation or exceeds the permitted use, you will need to obtain permission directly from the copyright holder. To view a copy of this licence, visit http//creativecommons.org/licenses/by/4.0/. The Creative Commons Public Domain Dedication waiver (http://creativecommons.org/publicdomain/zero/1.0/) applies to the data made available in this article, unless otherwise stated in a credit line to the data. 
pocket depth (PD) and clinical attachment level (CAL) and radiographic evidence of alveolar bone loss. Gingival bleeding and calculus are the prelude of occurrence of periodontal disease and they are also common in adolescents [5].

For the middle-school students, the periodontal problems usually performed as plaque, calculus, gingival bleeding, while shallow pocket depth and attachment loss were not common [6]. On the other hand, these periodontal diseases maintained at an early stage and reversible. In the group of 15-16-year-old adolescents of Finland, the prevalence of early periodontitis was between 10 and $15 \%$ [7].

The national oral health survey was conducted every 10 years and covered all provinces, municipalities, and autonomous regions. In the latest survey, it was found that gingival bleeding and calculus occurred more than six out of ten adolescents. In the 15-year-old population, $6.5 \%$ adolescents had periodontal pocket and $0.5 \%$ had attachment loss [8].

To investigate and further analyze the risk factors of Chinese adolescent's periodontal health, multi-factorial models of gingival bleeding and calculus were established in this study.

\section{Methods}

This study protocol was approved by the Ethics Committee of the Chinese Stomatological Association (Approval no. 2014-003). It was conducted from August 2015 to December 2016 in all 31 provinces, autonomous regions and municipalities of mainland China. Informed consent was obtained from all subjects or, if subjects are under 18, from a parent and/or legal guardian. All methods were carried out in accordance with relevant guidelines and regulations.

\section{Sampling}

In this study, sample size was calculated based on the data of third national oral health survey, in which the prevalence of gingival bleeding, calculus and dental caries were $59.1 \%, 57.7 \%$ and $28.9 \%$, respectively. Since this is a comprehensive oral health survey not only concerning periodontal disease, the lowest number of dental caries was chosen. The $95 \%$ confidence interval was set to $15 \%$ in 12-15 years old group and the designed effect was set to 4.5 . To meet the response rate of $80 \%$, the final sample size was 28,365 each for the $12-15$ years age groups.

A multistage cluster sampling was used in this study. First of all, two districts and two counties in each province were chosen randomly according to probability proportional to size (PPS) sampling. Secondly, three middles schools were selected in each district or county. Thirdly,
80 students in every age group were asked to participate in this survey by cluster sampling method.

\section{Clinical examination and questionnaire survey}

Gingival bleeding and calculus status were scored as 0 or 1 corresponding to absence or presence, respectively following the method of modified community periodontal index (CPI) recommended by WHO. Calibration training was carried out to ensure the reliability before the field work. Every clinical examiner was calibrated with a standard examiner and the kappa value was required to be higher than 0.6. At the survey site, $5 \%$ of subjects were randomly selected to finish the duplication for the surveillance of inter-examiner reliability. The kappa value was also required to be higher than 0.6.

A self-completed structured questionnaire was applied to collect data of participants' sociodemographic information (gender, age, etc.), oral health attitude, knowledge and behaviors (daily use of tooth brush and dental floss). Teachers and researchers would explain the content of this questionnaire before the adolescents completed the questions and answered the questions when they filled in the questionnaire.

\section{Data analysis}

All collected data was input into a dedicated National Survey data management system, and data of each subject was fed into computer for two times. If the two entries were inconsistent, the system would automatically give a reminder and the entry personnel would check and confirm correct data immediately. During the data entry process, logical check and normal value ranges were strictly preset.

Bivariate analysis was performed to investigate the relationship between periodontal status and relevant variables. The dependent dichotomous variables were gingival bleeding and calculus scored 0 or 1 . The independent variables were age, gender, region (east, middle and west), resident location (urban or rural), nation, family structure (one-child family or not), father and mother's educational level, smoking habit, brush teeth, using dental floss, oral health attitude and knowledge. All independent variables which were significant in the chisquare test were selected in the original binary logistic regression model (backward stepwise). Odds ratio with 95\% confidence interval was calculated to investigate the association among the periodontal status with other potential risk factors. As the random effect of the province variable, generalized linear mixed model (GLMM) was introduced in this study. The variable province was regarded as a fixed variable and the other significant relevant variables were entered in GLMM model. All the statistical significance was set as $P<0.05$. 


\section{Results}

Totally 118,514 subjects $(14.0 \pm 1.09$ years old $)$ participated in this survey. The prevalence of gingival bleeding and calculus was $61.0 \%$ and $67.3 \%$ respectively. With the increasing of the age, the periodontal status became worse $(P<0.001)$.

In the binary analysis, there were 13 variables associated with periodontal health, which were included in the logistic regression to analyze the multi-factorial effect on gingival bleeding. In the final model (Table 1), it was found that gender, age, region, living place, nation, family structure, parents' education level, dental hygiene habits and oral health knowledge were associated with gingival bleeding. The results were consistent with the binary analysis.

Males have more chance of gingival bleeding and the elder adolescents are more likely to have gingival bleeding than younger subjects. Adolescents living in eastern China relatively are not as susceptible as ones in western China. Subjects from one-child family and Han population have less chance of gingival bleeding. Fewer adolescents with higher educational parents suffered gingival bleeding. Good oral hygiene habit (brushing tooth) displayed greatest effect on prevent gingival bleeding. The adolescents who got lower oral health knowledge scores had higher chance of gingival bleeding.

Very similar results were shown in the Table 1, which presented the logistic regression model of calculus and associated factors (Table 2). With the increasing of age, more calculus was found in the mouth. The differences among regions became greater. And besides the same risk factors compared to the model of gingival bleeding, smoking habit was added. The smokers were more likely to have calculus than non-smokers.

The oral health knowledge and attitude of adolescents varies among provinces. For example, in some provinces, the proportion of adolescents with high scores in oral health knowledge ( $\geq 6$ right answers of 8 questions) was less than $20 \%$, but in the highest provinces it exceeded $60 \%$. The highest and lowest proportion of adolescents with positive oral health attitude was $73.9 \%$ and $49.3 \%$ respectively grouped by province. GLMM was applied to minimize the influence of province.

The results of GLMM showed that gender, age, living place, nation, father's education level, smoking, oral health knowledge and behavior were associated with gingival bleeding (Table 3). Male adolescents were more likely to have gingival bleeding. With the increasing of age, the risk of gingival bleeding increased. The subjects who lived in urban area were more likely to have gingival bleeding. Adolescents from Han ethnic group were less susceptible to gingival bleeding compared to those from other ethnic groups. Subjects with better oral hygiene behaviors were less likely to have bleeding on gingival. Gingival bleeding was less likely to occur among the subjects who got higher score in oral health knowledge.

The model of calculus was shown in Table 4. There were eight related factors and seven were same as those in gingival bleeding model. The same variables were gender, age, ethnic group, father education level, brush teeth, dental floss and oral health knowledge. The factor living place was not in this model compared with the model of gingival bleeding, and family structure seemed to present good effect on minimizing calculus. Participant's oral health attitude was not included in both generalized linear mixed model of gingival bleeding and calculus.

\section{Discussion}

The periodontal condition of Chinese adolescents was relatively unsatisfying, which was not improved compared to the situation 10 years ago. Most of the survey respondents had problems with gingival bleeding and calculus, which reflected that both parents and adolescents themselves lacked sufficient attention to periodontal health. The results of multivariate analysis showed that age, region, place of residence, family structure, parents 'education level, oral health behavior, and respondents' oral health knowledge were related to gingival bleeding and calculus. After adjusting the province's influence on the results, factors such as gender, age, ethnicity, father's education level, oral health knowledge and behavior were related to adolescent periodontal status.

The differences of periodontal status among different gender and age groups were found in several studies and consistent with the results in past national surveys $[9,10]$. Oral health behavior and knowledge also direct affected personal periodontal health $[11,12]$. The socio-economic factors, e.g. region, ethnical group, parents' education level, were related to adolescent's gingival bleeding and calculus.

The large difference among eastern, middle and western regions still existed. The periodontal status of teenagers in eastern region was obviously better than those in western region. There is a huge imbalance of economic development and medical resources among different regions in China. Periodontal diseases were more common in the less developed regions [13]. As the residences in the most developed region in China, adolescents in eastern region had greatly lower risk of periodontal disease compared to those in middle and western regions. A gratifying decline in the occurrence of gingival bleeding and calculus in the middle region has been achieved in the past decade [9]. This might be related to its quick development on economics and enhancement of oral health resources in twenty-first century. 
Table 1 Univariate and stepwise logistic regression on possible risk factor for gingival bleeding

\begin{tabular}{|c|c|c|c|c|c|c|c|c|}
\hline \multirow{3}{*}{$\begin{array}{l}\text { Factor } \\
\text { Gender }\end{array}$} & \multicolumn{5}{|c|}{ Univariate } & \multicolumn{3}{|c|}{ Stepwise } \\
\hline & \multirow[t]{2}{*}{$p$ value } & \multirow[t]{2}{*}{ OR } & \multicolumn{2}{|c|}{$95 \% \mathrm{Cl}$ for OR } & \multirow[t]{2}{*}{$p$ value } & \multirow[t]{2}{*}{ OR } & \multicolumn{2}{|c|}{$95 \% \mathrm{Cl}$ for OR } \\
\hline & & & & & & & & \\
\hline Male & $<0.001$ & 1.12 & 1.09 & 1.15 & $<0.001$ & 1.11 & 1.08 & 1.14 \\
\hline \multicolumn{9}{|l|}{ Female $^{a}$} \\
\hline Age & $<0.001$ & & & & $<0.001$ & & & \\
\hline 12 & & 0.77 & 0.74 & 0.79 & $<0.001$ & 0.75 & 0.72 & 0.78 \\
\hline 13 & & 0.82 & 0.79 & 0.85 & $<0.001$ & 0.81 & 0.78 & 0.84 \\
\hline 14 & & 0.85 & 0.82 & 0.88 & $<0.001$ & 0.83 & 0.80 & 0.86 \\
\hline \multicolumn{9}{|l|}{$15^{\mathrm{a}}$} \\
\hline Region & $<0.001$ & & & & $<0.001$ & & & \\
\hline East & & 0.81 & 0.79 & 0.84 & $<0.001$ & 0.86 & 0.83 & 0.89 \\
\hline West & & 1.19 & 1.15 & 1.22 & .004 & 1.05 & 1.02 & 1.09 \\
\hline \multicolumn{9}{|l|}{ Central $^{\mathrm{a}}$} \\
\hline \multicolumn{9}{|l|}{ Living place } \\
\hline Urban & $<0.001$ & 1.06 & 1.04 & 1.09 & 0.001 & 1.10 & 1.07 & 1.13 \\
\hline \multicolumn{9}{|l|}{ Rural $^{\mathrm{a}}$} \\
\hline \multicolumn{9}{|l|}{ Ethnic group } \\
\hline Han & $<0.001$ & 0.67 & 0.65 & 0.70 & $<0.001$ & 0.77 & 0.74 & 0.80 \\
\hline \multicolumn{9}{|l|}{ Minority $^{\mathrm{a}}$} \\
\hline \multicolumn{9}{|l|}{ Family structure } \\
\hline One-child family & $<0.001$ & 0.74 & 0.73 & 0.76 & $<0.001$ & 0.81 & 0.79 & 0.84 \\
\hline \multicolumn{9}{|l|}{ With siblings ${ }^{\mathrm{a}}$} \\
\hline Father education & $<0.001$ & & & & .001 & & & \\
\hline Middle school & & 1.50 & 1.44 & 1.56 & .005 & 1.09 & 1.03 & 1.15 \\
\hline High school & & 1.29 & 1.25 & 1.34 & $<0.001$ & 1.09 & 1.04 & 1.15 \\
\hline \multicolumn{9}{|l|}{ Univeristy $^{\mathrm{a}}$} \\
\hline Mother education & $<0.001$ & & & & .045 & & & \\
\hline Middle school & & 1.50 & 1.44 & 1.56 & .041 & 1.06 & 1.00 & 1.12 \\
\hline High school & & 1.25 & 1.21 & 1.30 & .397 & 1.02 & .97 & 1.07 \\
\hline \multicolumn{9}{|l|}{ Univerisity $^{\mathrm{a}}$} \\
\hline \multicolumn{9}{|l|}{ Smoking } \\
\hline Yes & $<0.001$ & 1.20 & 1.15 & 1.26 & & & & \\
\hline $\mathrm{No}^{\mathrm{a}}$ & & & & & & & & \\
\hline Brush teeth & & & & & & & & \\
\hline Yes & $<0.001$ & 0.64 & 0.61 & 0.66 & $<0.001$ & 0.69 & 0.66 & 0.73 \\
\hline $\mathrm{No}^{\mathrm{a}}$ & & & & & & & & \\
\hline Dental floss & & & & & & & & \\
\hline Yes & $<0.001$ & 0.81 & 0.78 & 0.84 & $<0.001$ & 0.89 & 0.85 & 0.93 \\
\hline $\mathrm{No}^{\mathrm{a}}$ & & & & & & & & \\
\hline Oral health knowledge & $<0.001$ & & & & $<0.001$ & & & \\
\hline $0-3$ & & 1.32 & 1.28 & 1.36 & $<0.001$ & 1.21 & 1.16 & 1.25 \\
\hline $4-5$ & & 1.18 & 1.15 & 1.22 & $<0.001$ & 1.12 & 1.09 & 1.16 \\
\hline $6-8^{\mathrm{a}}$ & & & & & & & & \\
\hline Oral health attitude & & & & & & & & \\
\hline Negative & 0.002 & 1.04 & 1.02 & 1.97 & & & & \\
\hline Positive $^{\mathrm{a}}$ & & & & & & & & \\
\hline Constant & & & & & $<0.001$ & 2.83 & & \\
\hline
\end{tabular}

${ }^{\mathrm{a}}$ Reference category 
Table 2 Univariate and stepwise logistic regression on possible risk factor for calculus

\begin{tabular}{|c|c|c|c|c|c|c|c|c|}
\hline \multirow{2}{*}{$\begin{array}{l}\text { Factor } \\
\text { Gender }\end{array}$} & \multicolumn{5}{|c|}{ Univariate } & \multicolumn{3}{|c|}{ Stepwise } \\
\hline & \multirow{3}{*}{$\begin{array}{l}p \text { value } \\
<0.001\end{array}$} & \multirow{3}{*}{$\begin{array}{l}\text { OR } \\
1.26\end{array}$} & \multicolumn{2}{|c|}{$95 \% \mathrm{Cl}$ for OR } & \multirow{2}{*}{$\begin{array}{l}p \text { value } \\
<0.001\end{array}$} & \multirow{2}{*}{$\begin{array}{l}\text { OR } \\
1.26\end{array}$} & \multicolumn{2}{|c|}{$95 \% \mathrm{Cl}$ for OR } \\
\hline Male & & & 1.23 & 1.29 & & & 1.22 & 1.30 \\
\hline \multicolumn{7}{|l|}{ Female $^{a}$} & & \\
\hline Age & $<0.001$ & & & & $<0.001$ & & & \\
\hline 12 & & 0.57 & 0.55 & 0.59 & $<0.001$ & 0.55 & 0.53 & 0.57 \\
\hline 13 & & 0.66 & 0.64 & 0.68 & $<0.001$ & 0.64 & 0.62 & 0.67 \\
\hline 14 & & 0.81 & 0.79 & 0.84 & $<0.001$ & 0.80 & 0.77 & 0.83 \\
\hline \multicolumn{9}{|l|}{$15^{\mathrm{a}}$} \\
\hline Region & $<0.001$ & & & & $<0.001$ & & & \\
\hline East & & 0.74 & 0.72 & 0.76 & $<0.001$ & 0.82 & 0.79 & 0.85 \\
\hline West & & 1.50 & 1.45 & 1.54 & $<0.001$ & 1.39 & 1.34 & 1.45 \\
\hline \multicolumn{9}{|l|}{ Central $^{\mathrm{a}}$} \\
\hline \multicolumn{9}{|l|}{ Living place } \\
\hline Urban & 0.001 & 0.96 & 0.94 & 0.98 & .069 & 1.02 & 1.00 & 1.06 \\
\hline \multicolumn{9}{|l|}{ Rural $^{a}$} \\
\hline \multicolumn{9}{|l|}{ Ethnic group } \\
\hline Han & $<0.001$ & 0.66 & 0.64 & 0.69 & .001 & 0.92 & 0.88 & 0.97 \\
\hline \multicolumn{9}{|l|}{ Minority ${ }^{\mathrm{a}}$} \\
\hline \multicolumn{9}{|l|}{ Family structure } \\
\hline One-child family & $<0.001$ & 0.68 & 0.66 & 0.69 & $<0.001$ & 0.78 & 0.76 & 0.81 \\
\hline \multicolumn{9}{|l|}{ With siblings $^{\mathrm{a}}$} \\
\hline Father education & $<0.001$ & & & & .002 & & & \\
\hline Middle school & & 1.86 & 1.78 & 1.94 & .001 & 1.11 & 1.04 & 1.17 \\
\hline High school & & 1.40 & 1.35 & 1.45 & .085 & 1.04 & 0.99 & 1.10 \\
\hline \multicolumn{9}{|l|}{ University $^{\mathrm{a}}$} \\
\hline Mother education & $<0.001$ & & & & $<0.001$ & & & \\
\hline Middle school & & 1.90 & 1.82 & 1.98 & $<0.001$ & 1.21 & 1.14 & 1.28 \\
\hline High school & & 1.39 & 1.34 & 1.44 & .001 & 1.09 & 1.04 & 1.15 \\
\hline \multicolumn{9}{|l|}{ University ${ }^{\mathrm{a}}$} \\
\hline \multicolumn{9}{|l|}{ Brush teeth } \\
\hline Yes & $<0.001$ & 0.61 & 0.58 & 0.63 & $<0.001$ & 0.69 & 0.66 & 0.73 \\
\hline $\mathrm{No}^{\mathrm{a}}$ & & & & & & & & \\
\hline Dental floss & & & & & & & & \\
\hline Yes & $<0.001$ & 0.67 & 0.64 & 0.69 & $<0.001$ & 0.78 & 0.75 & 0.82 \\
\hline $\mathrm{No}^{\mathrm{a}}$ & & & & & & & & \\
\hline Smoking & & & & & & & & \\
\hline Yes & $<0.001$ & 1.59 & 1.51 & 1.68 & .009 & 1.08 & 1.02 & 1.15 \\
\hline $\mathrm{No}^{\mathrm{a}}$ & & & & & & & & \\
\hline Oral health knowledge & & & & & $<0.001$ & & & \\
\hline $0-3$ & & 1.25 & 1.21 & 1.29 & $<0.001$ & 1.10 & 1.06 & 1.14 \\
\hline $4-5$ & & 1.24 & 1.20 & 1.27 & $<0.001$ & 1.13 & 1.09 & 1.16 \\
\hline $6-8^{\mathrm{a}}$ & & & & & & & & \\
\hline Oral health attitude & & & & & & & & \\
\hline Negative & 0.001 & 1.04 & 1.02 & 1.07 & & & & \\
\hline Positive $^{a}$ & & & & & & & & \\
\hline Constant & & & & & $<0.001$ & 3.30 & & \\
\hline
\end{tabular}

a Reference category 
Table 3 The generalized linear mixed model of gingival bleeding

\begin{tabular}{|c|c|c|c|c|c|}
\hline & \multirow[t]{2}{*}{ Coefficient } & \multirow[t]{2}{*}{ Sig. } & \multirow[t]{2}{*}{$\begin{array}{l}\text { Exp } \\
\text { (coefficient) }\end{array}$} & \multicolumn{2}{|c|}{$\begin{array}{l}\text { 95\% Cl for exp } \\
\text { (coefficient) }\end{array}$} \\
\hline & & & & Lower & Upper \\
\hline Intercept & 0.87 & & 2.39 & 1.52 & 3.75 \\
\hline \multicolumn{6}{|l|}{ Gender } \\
\hline Male & 0.11 & $<0.001$ & 1.12 & & \\
\hline Female $^{a}$ & & & & 1.09 & 1.15 \\
\hline \multicolumn{6}{|l|}{ Age } \\
\hline 12 & -0.35 & $<0.001$ & 0.70 & 0.67 & 0.73 \\
\hline 13 & -0.26 & $<0.001$ & 0.77 & 0.74 & 0.80 \\
\hline 14 & -0.22 & $<0.001$ & 0.80 & & \\
\hline $15^{\mathrm{a}}$ & & & & 0.77 & 0.83 \\
\hline \multicolumn{6}{|l|}{ Living place } \\
\hline Urban & 0.18 & $<0.001$ & 1.20 & & \\
\hline Rural $^{\mathrm{a}}$ & & & & 1.16 & 1.23 \\
\hline \multicolumn{6}{|l|}{ Ethnic group } \\
\hline Han & -0.08 & .003 & 0.92 & 0.87 & 0.97 \\
\hline \multicolumn{6}{|l|}{ Minority } \\
\hline \multicolumn{6}{|c|}{ Father education } \\
\hline Middle school & 0.18 & $<0.001$ & 1.20 & 1.140 & 1.26 \\
\hline High school & 0.12 & $<0.001$ & 1.14 & 1.09 & 1.18 \\
\hline \multicolumn{6}{|l|}{ University ${ }^{\mathrm{a}}$} \\
\hline \multicolumn{6}{|l|}{ Brush teeth } \\
\hline Yes & -0.29 & $<0.001$ & 0.75 & 0.71 & 0.79 \\
\hline \multicolumn{6}{|l|}{$\mathrm{No}^{\mathrm{a}}$} \\
\hline \multicolumn{6}{|l|}{ Dental floss } \\
\hline Yes & -0.20 & $<0.001$ & 0.82 & 0.78 & 0.86 \\
\hline \multicolumn{6}{|l|}{$\mathrm{No}^{\mathrm{a}}$} \\
\hline \multicolumn{6}{|c|}{ Oral health knowledge } \\
\hline $0-3$ & 0.09 & .002 & 1.09 & 1.05 & 1.13 \\
\hline $4-5$ & 0.06 & .001 & 1.06 & & \\
\hline $6-8^{\mathrm{a}}$ & & & & 1.03 & 1.10 \\
\hline
\end{tabular}

${ }^{a}$ Reference category

Han nation is the major nation with the largest population in China and the other 55 minority nations constitute about $10 \%$ of the population, around 140 million. In the previous surveys regarding the periodontal status of ethnic minorities in China, it was found that $93 \%$ of Dai children in 12 years old had gingivitis and $71 \%$ of Bulang children had bleeding gum [14]. The adolescents of ethnic minorities in China had a higher risk of periodontal disease compared to those of Han nation. Most of the ethnic minorities stay in rural area of middle and western regions, where dental resource is insufficient. The comparatively lower socio-economical level aggravates the inequality on dental resource [15].
Table 4 The generalized linear mixed model of calculus

\begin{tabular}{|c|c|c|c|c|c|}
\hline & \multirow[t]{2}{*}{ Coefficient } & \multirow[t]{2}{*}{ Sig. } & \multirow[t]{2}{*}{$\begin{array}{l}\text { Exp } \\
\text { (coefficient) }\end{array}$} & \multicolumn{2}{|c|}{$\begin{array}{l}95 \% \mathrm{Cl} \text { for exp } \\
\text { (coefficient) }\end{array}$} \\
\hline & & & & Lower & Upper \\
\hline Intercept & 1.17 & & 3.23 & 2.34 & 4.47 \\
\hline \multicolumn{6}{|l|}{ Gender } \\
\hline Male & 0.28 & $<0.001$ & 1.32 & 1.28 & 1.36 \\
\hline \multicolumn{6}{|l|}{ Female $^{a}$} \\
\hline \multicolumn{6}{|l|}{ Age } \\
\hline 12 & -0.67 & $<0.001$ & 0.51 & 0.49 & 0.53 \\
\hline 13 & -0.48 & $<0.001$ & 0.62 & 0.59 & 0.64 \\
\hline 14 & -0.25 & $<0.001$ & 0.78 & 0.75 & 0.82 \\
\hline \multicolumn{6}{|l|}{$15^{\mathrm{a}}$} \\
\hline \multicolumn{6}{|l|}{ Ethnic group } \\
\hline Han & -0.10 & .003 & 0.91 & 0.86 & 0.96 \\
\hline \multicolumn{6}{|l|}{ Minority $^{\mathrm{a}}$} \\
\hline \multicolumn{6}{|l|}{ Family structure } \\
\hline One-child family & -0.13 & $<0.001$ & 0.88 & 0.85 & 0.91 \\
\hline \multicolumn{6}{|c|}{ With siblings $^{\mathrm{a}}$} \\
\hline \multicolumn{6}{|l|}{ Father education } \\
\hline Middle school & 0.23 & $<0.001$ & 1.26 & 1.20 & 1.33 \\
\hline High school & 0.11 & $<0.001$ & 1.12 & 1.08 & 1.17 \\
\hline \multicolumn{6}{|l|}{ University ${ }^{\mathrm{a}}$} \\
\hline \multicolumn{6}{|l|}{ Brush teeth } \\
\hline Yes & -0.11 & $<0.001$ & 0.90 & 0.85 & 0.95 \\
\hline \multicolumn{6}{|l|}{$\mathrm{No}^{\mathrm{a}}$} \\
\hline \multicolumn{6}{|l|}{ Dental floss } \\
\hline Yes & -0.18 & $<0.001$ & 0.83 & 0.79 & 0.87 \\
\hline \multicolumn{6}{|l|}{$\mathrm{No}^{\mathrm{a}}$} \\
\hline \multicolumn{6}{|c|}{ Oral health knowledge } \\
\hline $0-3$ & 0.06 & .002 & 1.06 & 1.02 & 1.11 \\
\hline $4-5$ & 0.06 & .001 & 1.06 & 1.03 & 1.09 \\
\hline $6-8^{a}$ & & & & & \\
\hline
\end{tabular}

China is a vast and densely populated country, where the differences in economic development level among different provinces and cities were huge. For example, cities with high levels of economic development have a per capita GDP of more than US \$20,000, which is close to that of developed countries. However, the province with the worst economic development is only a quarter of the formers, and it is still underdeveloped [10]. In addition, many provinces and cities have different living habits, education levels and medical resources. Therefore, it was relatively simple and rough to divide all provinces, autonomous regions, and municipalities into three regions (east, middle, and west) according to the geographical location and the degree of economic development. In order to get further understand 
whether the differences among provinces and cities affect the periodontal status of adolescents, we also used the province as a separate variable to sort out the relevant influencing factors of adolescents' periodontal status. The generalized linear mixed model was applied while province was considered as a random variable [16].

After the adjustment of province, several common factors left in gingival bleeding and calculus models (shown in Table 3,4). This result gave us a great hint that, in China, the impact of different provinces might exceed the impact of individual factors. The province variable is a variable integrates multiple economic factors, such as ethnicity, family structure, and other factors. Therefore, it was not only necessary to explore common influences across the country, various situations in different provinces should also be taken into consideration.

This study had several limitations. First of all, this was a cross-sectional study, which could not identify the cause-effect relationship between risk factors and outcomes. However, the risk factors found in this study would provide information for the further longitudinal study. Second, CPI was used in this study. Community Periodontal Index (CPI) was originated from Community Periodontal Index of Treatment Needs (CPITN) and modified to include all teeth in all four quadrants [17]. CPI/CPITN was not sensitive for the prevalence estimate of $\mathrm{PD} \geq 6 \mathrm{~mm}$ and also not accurate enough for the estimates of periodontitis extent [18]. This index was design for large-scale screening but not diagnosed for gingivitis and periodontitis [19]. Thus, it was hard to estimate the prevalence of gingivitis and periodontitis of Chinese adolescents from this study.

Gingival bleeding is the primary symptom of gingival disease. The high prevalence of gingival bleeding and calculus indicated the potential risk of gingivitis and poor oral hygiene in Chinese adolescents. If this situation did not attract public's attention, more patients with periodontal disease would appear in the future. China has been facing severe periodontal disease and tooth loss status in adult and elderly populations. The prevalence of clinical attachment loss (CAL $>3 \mathrm{~mm}$ ) was $33.2 \%$ among 35-44-year-old Chinese adults [20], and mean of remaining teeth was 22.5 in 65-74-year-old group [21]. Effort and support on oral health shall been delivered to adolescents to avoid same similar situation happening again in next generation.

\section{Conclusions}

Gingival bleeding and calculus occurred most of 12-15 years old adolescents in China. Several related factors, such as gender, age, ethnicity, father's education level, oral health knowledge and behavior, were found in multi-factorial models. The impact of province should arouse people's attention.

\section{Abbreviations}

PD: Probing pocket depth; CAL: Clinical attachment level; CPI: Community periodontal index.

\section{Acknowledgements}

The authors would like to thank the patients and their parents, who agreed to participate in this study.

\section{Authors' contributions \\ $X C$, JY-Z and $Y Z$ contributed to the literature review, study concept and design, data analysis and drafted the manuscript; XW, XP-F, BJ-T, DY-H, HC-L, BW, YS, CX-W, GS-Z, XN-L, WS-R and WJ-W trained the investigators, designed and supervised the survey; XP-F contributed to study concept and design, data acquisition, organization and supervision of study, and critically revised the manuscript. All authors have read and approved the final manuscript.}

\section{Funding}

The research was supported by the Scientific Research Fund of National Health Commission of the People's Republic of China (201502002) and Shanghai Municipal Health Commision (2019SY027, 2020YJZX0114). The fund was used for providing the materials. The funders provided quality supervision in this study and had no role in study design, data collection and analysis, writing the manuscript, decision to publish, or preparation of manuscript.

\section{Availability of data and materials}

All data generated or analyzed during this study are included in this published article.

\section{Declarations}

Ethics approval and consent to participate

This study protocol was approved by the Ethics Committee of the Chinese Stomatological Association (Approval no. 2014-003). Informed consent was obtained from all subjects or, if subjects are under 18 , from a parent and/or legal guardian.

\section{Consent for publication}

Not applicable.

\section{Competing interests}

The authors declare that they have no conflict of interest.

\section{Author details}

${ }^{1}$ Shanghai Key Laboratory of Stomatology and Shanghai Research Institute of Stomatology, Department of Preventive Dentistry, Shanghai Ninth People's Hospital, College of Stomatology, National Clinical Research Center for Oral Diseases, Shanghai Jiao Tong University School of Medicine, 639 Zhizaoju Road, Shanghai, People's Republic of China. ${ }^{2}$ Chinese Stomatological Association, Beijing, People's Republic of China. ${ }^{3}$ School and Hospital of Stomatology, Wuhan University, Wuhan, People's Republic of China. ${ }^{4}$ West China Hospital of Stomatology, Sichuan University, Chengdu, People's Republic of China. ${ }^{5}$ Guanghua School of Stomatology, Hospital of Stomatology, Sun Yat- Sen University, Guangzhou, People's Republic of China. ${ }^{6}$ Peking University School and Hospital of Stomatology, Beijing, People's Republic of China. ${ }^{7}$ Chinese Center for Disease Control and Prevention, Beijing, People's Republic of China.

Received: 17 April 2021 Accepted: 21 September 2021

Published online: 12 October 2021

\section{References}

1. Frencken JE, Sharma P, Stenhouse L, Green D, Laverty D, Dietrich T. Global epidemiology of dental caries and severe periodontitis - a comprehensive review. J Clin Periodontol. 2017;44(S18):S94-105. 
2. Kassebaum NJ, Smith AGC, Bernabe E, Fleming TD, Reynolds AE, Vos T, et al. Global, regional, and national prevalence, incidence, and disabilityadjusted life years for oral conditions for 195 countries, 1990-2015: a systematic analysis for the global burden of diseases, injuries, and risk factors. J Dent Res. 2017;96(4):380-7.

3. Tonetti MS, Jepsen S, Jin L, Otomo-Corgel J. Impact of the global burden of periodontal diseases on health, nutrition and wellbeing of mankind: a call for global action. J Clin Periodontol. 2017;44(5):456-62.

4. Williams RC. Periodontal disease. N Engl J Med. 1990;322(6):373-82.

5. Nicolau B, Marcenes W, Hardy R, Sheiham A. A life-course approach to assess the relationship between social and psychological circumstances and gingival status in adolescents. J Clin Periodontol. 2003;30(12):1038-45.

6. Jin LJ, Armitage GC, Klinge B, Lang NP, Tonetti M, Williams RC. Global oral health inequalities: task group-periodontal disease. Adv Dent Res. 2011;23(2):221-6.

7. Heikkinen AM, Pajukanta R, Pitkaniemi J, Broms U, Sorsa T, Koskenvuo M, et al. The effect of smoking on periodontal health of 15- to 16-year-old adolescents. J Periodontol. 2008;79(11):2042-7.

8. Chen X, Ye W, Zhan JY, Wang X, Tai BJ, Hu Y, et al. Periodontal status of Chinese adolescents: findings from the 4 th national oral health survey. Chin J Dent Res. 2018;21(3):195-203.

9. Wang HY, Petersen PE, Bian JY, Zhang BX. The second national survey of oral health status of children and adults in China. Int Dent J. 2002;52(4):283-90.

10. Lu HX, Tao DY, Lo ECM, Li R, Wang X, Tai BJ, et al. The 4th national oral health survey in the mainland of China: background and methodology. Chin J Dent Res. 2018;21(3):161-5.

11. Genco RJ, Borgnakke WS. Risk factors for periodontal disease. Periodontol 2000. 2013;62(1):59-94.

12. Sanz M, D'Aiuto F, Deanfield J, Fernandez-Avilés F. European workshop in periodontal health and cardiovascular disease-scientific evidence on the association between periodontal and cardiovascular diseases: a review of the literature. Eur Heart J Suppl. 2010;12(suppl_B):B3-12.
13. Holtfreter B, Kocher T, Hoffmann T, Desvarieux M, Micheelis W. Prevalence of periodontal disease and treatment demands based on a German dental survey (DMS IV). J Clin Periodontol. 2010;37(3):211-9.

14. Zhang S, Xu B, Liu J, Lo EC, Chu CH. Dental and periodontal status of 12-year-old Dai school children in Yunnan Province, China: a cross-sectional study. BMC Oral Health. 2015;15(1):117.

15. Eke PI, Dye BA, Wei L, Slade GD, Thornton-Evans GO, Borgnakke WS, et al. Update on prevalence of periodontitis in adults in the United States: NHANES 2009 to 2012. J Periodontol. 2015;86(5):611-22.

16. Gilmour AR, Anderson RD, Rae AL. The analysis of binomial data by a generalized linear mixed model. Biometrika. 1985;72(3):593-9.

17. World Health Organization. Oral health surveys: basic methods: World Health Organization; 2013.

18. Tran DT, Gay I, Du XL, Fu Y, Bebermeyer RD, Neumann AS, et al. Assessing periodontitis in populations: a systematic review of the validity of partialmouth examination protocols. J Clin Periodontol. 2013;40(12):1064-71.

19. Trombelli L, Farina R, Silva CO, Tatakis DN. Plaque-induced gingivitis: case definition and diagnostic considerations. J Periodontol. 2018;89(S1):S46-73

20. Sun $H Y$, Jiang $H$, Du $M Q$, Wang $X$, Feng $X P, H u Y$, et al. The prevalence and associated factors of periodontal disease among 35 to 44-year-old Chinese adults in the 4th national oral health survey. Chin J Dent Res. 2018;21(4):241-7.

21. Guo J, Ban JH, Li G, Wang X, Feng XP, Tai BJ, et al. Status of tooth loss and denture restoration in Chinese adult population: findings from the 4th national oral health survey. Chin J Dent Res Off J Sci Sect Chin Stomatol Assoc (CSA). 2018;21(4):249-57.

\section{Publisher's Note}

Springer Nature remains neutral with regard to jurisdictional claims in published maps and institutional affiliations.
Ready to submit your research? Choose BMC and benefit from:

- fast, convenient online submission

- thorough peer review by experienced researchers in your field

- rapid publication on acceptance

- support for research data, including large and complex data types

- gold Open Access which fosters wider collaboration and increased citations

- maximum visibility for your research: over $100 \mathrm{M}$ website views per year

At BMC, research is always in progress.

Learn more biomedcentral.com/submissions 